\title{
Anti L-Fuzzy Normal M-Subgroups
}

\author{
P.Pandiammal \\ Department of Mathematics, \\ PSNA College of Engineering \\ and Technology, \\ Dindigul, Tamil Nadu,
}

\author{
R.Natarajan \\ HOD, Department of \\ Mathematics, Alagappa \\ University, \\ Karaikudi-630 003, Tamil Nadu,
}

\author{
N.Palaniappan \\ Department of Mathematics, \\ Alagappa University, Karaikudi- \\ 630 003, Tamil Nadu, India
}

\begin{abstract}
This paper contains some definitions and results of anti L-fuzzy normal M-subgroup is being given. Using homomorphism and anti-homomorphism, anti L-fuzzy normal M-subgroups is studied. Some properties of anti L-fuzzy normal M-subgroups are also established.
\end{abstract}

Keywords: L-fuzzy subset, anti L-fuzzy M-subgroup, anti L-fuzzy normal M-subgroup, anti L-fuzzy characteristic Msubgroup, homomorphism, anti-homomorphism

\section{INTRODUCTION}

The notion of fuzzy sets was introduced by L.A. Zadeh [10]. Fuzzy set theory has been developed in many directions by many researchers and has evoked great interest among mathematicians working in different fields of mathematics, such as topological spaces, functional analysis, loop, group, ring, near ring, vector spaces, automation. In 1971, Rosenfield [1] introduced the concept of fuzzy subgroup. Motivated by this, many mathematicians started to review various concepts and theorems of abstract algebra in the broader frame work of fuzzy settings. In [2], Biswas introduced the concept of anti- fuzzy subgroups of groups. Palaniappan. N and Muthuraj, [6] defined the homomorphism, anti-homomorphism of a fuzzy and an anti-fuzzy groups. In this paper we define a new algebraic structure of anti L-fuzzy Normal M-subgroups and study some their related properties.

\section{PRELIMINARIES}

1.1 Definition: Let $G$ be a M-group. A L-fuzzy subset A of $G$ is said to be an anti L-fuzzy M-subgroup (ALFMSG) of G if its satisfies the following axioms:

(i) $\quad \mu_{\mathrm{A}}(\mathrm{mxy}) \leq \mu_{\mathrm{A}}(\mathrm{x}) \vee \mu_{\mathrm{A}}(\mathrm{y})$,

(ii) $\mu_{\mathrm{A}}\left(\mathrm{x}^{-1}\right) \leq \mu_{\mathrm{A}}(\mathrm{x})$, for all $\mathrm{x}$ and $\mathrm{y}$ in $\mathrm{G}$.

1.2 Definition: Let A and B be two anti L-fuzzy M-subgroups of a M-group G. Then A and B are said to be conjugate anti Lfuzzy M-subgroups of $\mathrm{G}$ if for some $\mathrm{g} \in \mathrm{G}, \mu_{\mathrm{A}}(\mathrm{x})=\mu_{\mathrm{B}}\left(\mathrm{g}^{-1} \mathrm{xg}\right)$, for every $x$ in $G$.

1.3 Definition: Let $G$ be a M-group. An anti L-fuzzy Msubgroup $A$ of $G$ is said to be anti L-fuzzy normal Msubgroup (ALFNMSG) of G if $\mu_{A}(x y)=\mu_{A}(y x)$, for all $x$ and $y$ in $\mathrm{G}$.
1.4 Definition: Let $G$ be a M-group. An anti L-fuzzy Msubgroup A of $G$ is said to be an anti L-fuzzy characteristic $M$ subgroup (ALFCMSG) of $G$ if $\mu_{A}(x)=\mu_{A}(f(x))$, for all $x$ in $G$ and $\mathrm{f}$ in AutG.

\section{SOME PROPERTIES OF ANTI L- FUZZY NORMAL M-SUBGROUPS}

2.1 Theorem: Let $\mathrm{G}$ be a M-group. If $\mathrm{A}$ and $\mathrm{B}$ are two anti $\mathrm{L}-$ fuzzy normal M-subgroups of $G$, then their intersection $A \cap B$ is an anti L-fuzzy normal M-subgroup of G.

Proof: Let $\mathrm{x}$ and $\mathrm{y}$ in $\mathrm{G}$. Let $\mathrm{A}=\left\{\left\langle\mathrm{x}, \mu_{\mathrm{A}}(\mathrm{x})\right\rangle / \mathrm{x} \in \mathrm{G}\right\}$ and $\mathrm{B}=$ $\left\{\left\langle\mathrm{x}, \mu_{\mathrm{B}}(\mathrm{x})\right\rangle / \mathrm{x} \in \mathrm{G}\right\}$

be an anti L-fuzzy normal M-subgroups of a M-group $\mathrm{G}$.

Let $\mathrm{C}=\mathrm{A} \cap \mathrm{B}$ and $\mathrm{C}=\left\{\left\langle\mathrm{x}, \mu_{\mathrm{C}}(\mathrm{x})\right\rangle / \mathrm{x} \in \mathrm{G}\right\}$.

Then, we know that $\mathrm{C}$ is an anti L-fuzzy M-subgroup of a Mgroup G,

since A and B are two anti L-fuzzy M-subgroups of a M-group G.

And, $\mu_{\mathrm{C}}(\mathrm{xy})=\mu_{\mathrm{A}}(\mathrm{xy}) \wedge \mu_{\mathrm{B}}(\mathrm{xy})$, as $\mathrm{A}$ and $\mathrm{B}$ are an ALFNMSGs of a M-group $\mathrm{G}$.

$$
=\mu_{\mathrm{A}}(\mathrm{yx}) \wedge \mu_{\mathrm{B}}(\mathrm{yx})=\mu_{\mathrm{C}}(\mathrm{yx}) .
$$

Therefore, $\mu_{\mathrm{C}}(\mathrm{xy})=\mu_{\mathrm{C}}(\mathrm{yx})$.

Hence $A \cap B$ is an anti L-fuzzy normal M-subgroup of a Mgroup $\mathrm{G}$.

2.2 Theorem: Let $\mathrm{G}$ be a M-group. The intersection of a family of anti L-fuzzy normal M-subgroups of $\mathrm{G}$ is an anti Lfuzzy normal M-subgroup of $\mathrm{G}$.

Proof: Let $\left\{\mathrm{A}_{\mathrm{i}}\right\}_{\mathrm{i} \in \mathrm{I}}$ be a family of anti L-fuzzy normal Msubgroups of a M-group $G$ and let $A=\cap A_{i}$. Then for $x$ and $y$ in G. We know that, the intersection of a family of anti L-fuzzy M-subgroups of a M-group G is an anti L-fuzzy M-subgroup of a M-group G.

$$
\begin{aligned}
& \text { Now, } \mu_{\mathrm{A}}(\mathrm{xy})=\inf _{i \in I} \mu_{A_{i}}(x y) \\
& =\inf _{i \in I} \mu_{A_{i}}(y x) \text {, as }\left\{\mathrm{A}_{\mathrm{i}}\right\}_{\mathrm{i} \in \mathrm{I}} \text { are } \\
& =\mu_{\mathrm{A}}(\mathrm{yx}) \text {. } \\
& \text { ALFNMSG of a M-group G }
\end{aligned}
$$

Therefore, $\mu_{\mathrm{A}}(\mathrm{xy})=\mu_{\mathrm{A}}(\mathrm{yx})$. 
Hence the intersection of a family of anti L-fuzzy normal Msubgroups of a normal M-subgroup of a M-group G.

$M$-group $\mathrm{G}$ is an anti L-fuzzy

2.3 Theorem: If $\mathrm{A}$ is an anti L-fuzzy characteristic M-subgroup of a M-group $\mathrm{G}$, then $\mathrm{A}$ is an anti L-fuzzy normal M-subgroup of a M-group $\mathrm{G}$.

Proof: Let A be an anti L-fuzzy characteristic M-subgroup of a M-group $G$ and let $x$ and $y$ in $G$. Consider the map $f: G \rightarrow G$ defined by

$f(x)=y_{x y}{ }^{-1}$.

We know that, $f \in$ AutG.

Now,

$$
\begin{aligned}
\mu_{\mathrm{A}}(\mathrm{xy})= & \mu_{\mathrm{A}}(\mathrm{f}(\mathrm{xy})), \\
& \text { as } \mathrm{A} \text { is an ALFCMSG of a M-group } \mathrm{G} \\
= & \mu_{\mathrm{A}}\left(\mathrm{y}(\mathrm{xy}) \mathrm{y}^{-1}\right) \\
= & \mu_{\mathrm{A}}(\mathrm{yx}) .
\end{aligned}
$$

Therefore, $\mu_{\mathrm{A}}(\mathrm{xy})=\mu_{\mathrm{A}}(\mathrm{yx})$.

Hence A is an anti L-fuzzy normal M-subgroup of a M-group G.

2.4 Theorem: An anti L-fuzzy M-subgroup A of a M-group G is an anti L-fuzzy normal M-subgroup of $\mathrm{G}$ if and only if $\mathrm{A}$ is constant on the conjugate classes of $\mathrm{G}$.

Proof: Suppose that A is an anti L-fuzzy normal M-subgroup of a $\mathrm{M}$-group $\mathrm{G}$ and let $\mathrm{x}$ and $\mathrm{y}$ in $\mathrm{G}$. Now,

$$
\begin{aligned}
\mu_{\mathrm{A}}\left(\mathrm{y}^{-1} \mathrm{xy}\right)= & \mu_{\mathrm{A}}\left(\mathrm{xyy}^{-1}\right), \\
& \text { since A is an ALFNMSG of } \mathrm{G} \\
= & \mu_{\mathrm{A}}(\mathrm{x}) .
\end{aligned}
$$

Therefore, $\mu_{\mathrm{A}}\left(\mathrm{y}^{-1} \mathrm{xy}\right)=\mu_{\mathrm{A}}(\mathrm{x})$.

Hence $(x)=\left\{y^{-1} x y / y \in G\right\}$.

Hence $\mathrm{A}$ is constant on the conjugate classes of $\mathrm{G}$.

Conversely, suppose that $\mathrm{A}$ is constant on the conjugate classes of $\mathrm{G}$.

$$
\begin{aligned}
& \text { Then, } \mu_{A}(x y)=\mu_{A}\left(x_{x y x} x^{-1}\right) \\
& =\mu_{\mathrm{A}}\left(\mathrm{x}(\mathrm{yx}) \mathrm{x}^{-1}\right) \text {, as } \mathrm{A} \text { is constant } \\
& \text { on the conjugate classes of } G \\
& =\mu_{\mathrm{A}}(\mathrm{yx}) \text {. }
\end{aligned}
$$

Therefore, $\mu_{\mathrm{A}}(\mathrm{xy})=\mu_{\mathrm{A}}(\mathrm{yx})$.

Hence A is an anti L-fuzzy normal M-subgroup of a M-group G.

2.5 Theorem: Let A be an anti L-fuzzy normal M-subgroup of a M-group $G$. Then for any $y \in G$ we have $\mu_{A}\left(y x y^{-1}\right)=\mu_{A}\left(y^{-1} x y\right)$, for every $\mathrm{x} \in \mathrm{G}$.

Proof: Let A be an anti L-fuzzy normal M-subgroup of a Mgroup $\mathrm{G}$.

For any $y \in G$, we have,

$$
\begin{aligned}
\mu_{\mathrm{A}}\left(\mathrm{yxy}^{-1}\right)= & \mu_{\mathrm{A}}\left(\mathrm{y}^{-1} \mathrm{yx}\right) \\
= & \mu_{\mathrm{A}}(\mathrm{x}), \\
& \quad \text { since } \mathrm{A} \text { is an ALFNMSG of } \mathrm{G} \\
= & \mu_{\mathrm{A}}\left(\mathrm{xyy}^{-1}\right), \\
& \quad \text { since } \mathrm{A} \text { is an ALFNMSG of } \mathrm{G} \\
= & \mu_{\mathrm{A}}\left(\mathrm{y}^{-1} \mathrm{xy}\right) .
\end{aligned}
$$

Therefore, $\mu_{\mathrm{A}}\left(\mathrm{yxy}^{-1}\right)=\mu_{\mathrm{A}}\left(\mathrm{y}^{-1} \mathrm{xy}\right)$, for all $\mathrm{x}$ and $\mathrm{y}$ in $\mathrm{G}$.

2.6 Theorem: Let A and B be anti L-fuzzy M-subgroups of Mgroups $\mathrm{G}$ and $\mathrm{H}$, respectively. If $\mathrm{A}$ and $\mathrm{B}$ are anti L-fuzzy normal M-subgroups, then AxB is an anti L-fuzzy normal Msubgroup of GxH.

Proof: Let A and B be an anti L-fuzzy normal M-subgroups of the $\mathrm{M}$-groups $\mathrm{G}$ and $\mathrm{H}$ respectively. We know that $\mathrm{AxB}$ is an anti L-fuzzy M-subgroup of GxH.

Let $x_{1}$ and $x_{2}$ be in $G, y_{1}$ and $y_{2}$ be in $H$.

Then $\left(\mathrm{x}_{1}, \mathrm{y}_{1}\right)$ and $\left(\mathrm{x}_{2}, \mathrm{y}_{2}\right)$ are in $\mathrm{GxH}$.

$$
\begin{aligned}
& \text { Now, } \mu_{\mathrm{AxB}}\left[\left(\mathrm{x}_{1}, \mathrm{y}_{1}\right)\left(\mathrm{x}_{2}, \mathrm{y}_{2}\right)\right]=\mu_{\mathrm{AxB}}\left(\mathrm{x}_{1} \mathrm{x}_{2}, \mathrm{y}_{1} \mathrm{y}_{2}\right) \\
&= \mu_{\mathrm{A}}\left(\mathrm{x}_{1} \mathrm{x}_{2}\right) \vee \mu_{\mathrm{B}}\left(\mathrm{y}_{1} \mathrm{y}_{2}\right) \\
&= \mu_{\mathrm{A}}\left(\mathrm{x}_{2} \mathrm{x}_{1}\right) \vee \mu_{\mathrm{B}}\left(\mathrm{y}_{2} \mathrm{y}_{1}\right), \\
& \quad \text { since A and B are ALFNMSGs of the } \\
& \text { groups } \mathrm{A} \text { and } \mathrm{H}= \\
&= \mu_{\mathrm{AxB}}\left(\mathrm{x}_{2} \mathrm{x}_{1}, \mathrm{y}_{2} \mathrm{y}_{1}\right) \\
&= \mu_{\mathrm{AxB}}\left[\left(\mathrm{x}_{2}, \mathrm{y}_{2}\right)\left(\mathrm{x}_{1}, \mathrm{y}_{1}\right)\right] .
\end{aligned}
$$

Therefore, $\mu_{\mathrm{AxB}}\left[\left(\mathrm{x}_{1}, \mathrm{y}_{1}\right)\left(\mathrm{x}_{2}, \mathrm{y}_{2}\right)\right]=$ $\mu_{\mathrm{AxB}}\left[\left(\mathrm{x}_{2}, \mathrm{y}_{2}\right)\left(\mathrm{x}_{1}, \mathrm{y}_{1}\right)\right]$.

Hence $\mathrm{AxB}$ is an anti L-fuzzy normal M-subgroup of GxH.

2.7 Theorem: Let an anti L-fuzzy normal M-subgroup A of a M-group $\mathrm{G}$ be conjugate to an anti L-fuzzy normal Msubgroup M of G and an anti L-fuzzy normal M-subgroup B of a M-group $\mathrm{H}$ be conjugate to an anti L-fuzzy normal M-subgroup $\mathrm{N}$ of $\mathrm{H}$. Then an anti L-fuzzy normal M-subgroup AxB of a $\mathrm{M}$ group $\mathrm{GxH}$ is conjugate to an anti L-fuzzy normal M-subgroup $\mathrm{MxN}$ of $\mathrm{GxH}$.

Proof: Let A and B be anti L-fuzzy normal M-subgroups of the $\mathrm{M}$-groups $\mathrm{G}$ and $\mathrm{H}$ respectively. Let $\mathrm{x}, \mathrm{x}^{-1}$ and $\mathrm{f}$ be in $\mathrm{G}$ and $\mathrm{y}$, $\mathrm{y}^{-1}$ and $\mathrm{g}$ be in $\mathrm{H}$.

Then $(\mathrm{x}, \mathrm{y}),\left(\mathrm{x}^{-1}, \mathrm{y}^{-1}\right)$ and (f, g) are in GxH.

Now, $\mu_{\mathrm{AxB}}(\mathrm{f}, \mathrm{g})=\mu_{\mathrm{A}}(\mathrm{f}) \vee \mu_{\mathrm{B}}(\mathrm{g})$

$$
=\mu_{\mathrm{M}}\left(\mathrm{xf} \mathrm{x}^{-1}\right) \vee \mu_{\mathrm{N}}\left(\mathrm{yg} \mathrm{y}^{-1}\right) \text {, }
$$

(since ALFNMSGs $\mathrm{A}$ and $\mathrm{B}$ of $\mathrm{M}$-groups $\mathrm{G}$ and $\mathrm{H}$ are conjugate to ALFNMSGs $\mathrm{M}$ and $\mathrm{N}$ of $\mathrm{G}$ and $\mathrm{H}$.)

$$
\begin{aligned}
& =\mu_{\mathrm{MxN}}\left(\mathrm{xf} \mathrm{x}^{-1}, \mathrm{yg} \mathrm{y}^{-1}\right) \\
& =\mu_{\mathrm{MxN}}\left[(\mathrm{x}, \mathrm{y})(\mathrm{f}, \mathrm{g})\left(\mathrm{x}^{-1}, \mathrm{y}^{-1}\right)\right] \\
& =\mu_{\mathrm{MxN}}\left[(\mathrm{x}, \mathrm{y})(\mathrm{f}, \mathrm{g})(\mathrm{x}, \mathrm{y})^{-1}\right] .
\end{aligned}
$$

Therefore, $\mu_{\mathrm{AxB}}(\mathrm{f}, \mathrm{g})=\mu_{\mathrm{MxN}}\left[(\mathrm{x}, \mathrm{y})(\mathrm{f}, \mathrm{g})(\mathrm{x}, \mathrm{y})^{-1}\right]$.

Hence an anti L-fuzzy Normal M-subgroup AxB of a M-group $\mathrm{GxH}$ is conjugate to an anti L-fuzzy Normal M-subgroup $\mathrm{MxN}$ of $\mathrm{GxH}$.

2.8 Theorem: Let A and B be L-fuzzy subsets of the Mgroups $\mathrm{G}$ and $\mathrm{H}$, respectively. Suppose that $\mathrm{e}$ and $\mathrm{e}$ 'are the identity element of $\mathrm{G}$ and $\mathrm{H}$, respectively. If $\mathrm{AxB}$ is an anti $\mathrm{L}-$ fuzzy normal M-subgroup of $\mathrm{GxH}$, then at least one of the following two statements must hold.

(i) $\mu_{\mathrm{B}}\left(\mathrm{e}^{\mathrm{l}}\right) \leq \mu_{\mathrm{A}}(\mathrm{x})$, for all $\mathrm{x}$ in $\mathrm{G}$,

(ii) $\mu_{A}($ e $) \leq \mu_{B}(y)$, for all $y$ in $H$. 
Proof: Let $\mathrm{AxB}$ is an anti L-fuzzy Normal M-subgroup of GxH.

By contraposition, suppose that none of the statements (i) and (ii) holds.

Then we can find $\mathrm{a}$ in $\mathrm{G}$ and $\mathrm{b}$ in $\mathrm{H}$ such that $\mu_{\mathrm{A}}(\mathrm{a})<\mu_{\mathrm{B}}\left(\mathrm{e}^{\prime}\right)$ and $\mu_{\mathrm{B}}(\mathrm{b})<\mu_{\mathrm{A}}(\mathrm{e})$.

We have, $\mu_{\mathrm{AxB}}(\mathrm{a}, \mathrm{b})=\mu_{\mathrm{A}}(\mathrm{a}) \vee \mu_{\mathrm{B}}(\mathrm{b})$

$$
\begin{aligned}
& <\mu_{\mathrm{A}}(\mathrm{e}) \vee \mu_{\mathrm{B}}\left(\mathrm{e}^{\mathrm{l}}\right) \\
& =\mu_{\mathrm{AxB}}\left(\mathrm{e}, \mathrm{e}^{\mathrm{l}}\right) .
\end{aligned}
$$

Thus AxB is not an anti L-fuzzy Normal M-subgroup of GxH. Hence either $\mu_{B}\left(e^{\prime}\right) \leq \mu_{A}(x)$, for all $x$ in $G$ or $\mu_{A}(e) \leq \mu_{B}(y)$, for all $\mathrm{y}$ in $\mathrm{H}$.

2.9 Theorem: Let A and B be L-fuzzy subsets of the Mgroups $\mathrm{G}$ and $\mathrm{H}$, respectively and $\mathrm{AxB}$ is an anti L-fuzzy normal M-subgroup of $\mathrm{GxH}$.

Then the following are true:

(i) if $\mu_{\mathrm{A}}(\mathrm{x}) \geq \mu_{\mathrm{B}}\left(\mathrm{e}^{\prime}\right)$, then $\mathrm{A}$ is an anti L-fuzzy normal M-subgroup of $\mathrm{G}$.

(ii) if $\mu_{\mathrm{B}}(\mathrm{x}) \geq \mu_{\mathrm{A}}$ ( e ), then $\mathrm{B}$ is an anti L-fuzzy normal M-subgroup of $\mathrm{H}$.

(iii) either $\mathrm{A}$ is an anti L-fuzzy normal M-subgroup of $\mathrm{G}$ or $\mathrm{B}$ is an anti L-fuzzy normal M-subgroup of $\mathrm{H}$.

Proof: Let $\mathrm{AxB}$ be an anti L-fuzzy Normal M-subgroup of $\mathrm{GxH}$ and $\mathrm{x}, \mathrm{y}$ in $\mathrm{G}$.

Then $\left(x, e^{\prime}\right)$ and $\left(y, e^{\prime}\right)$ are in GxH. Now, using the property $\mu_{\mathrm{A}}(\mathrm{x}$ )$\geq \mu_{\mathrm{B}}\left(\mathrm{e}^{\prime}\right)$, for all $\mathrm{x}$ in $\mathrm{G}$,

we get, $\mu_{\mathrm{A}}\left(\mathrm{xy}^{-1}\right)=\mu_{\mathrm{A}}\left(x y^{-1}\right) \vee \mu_{\mathrm{B}}\left(\mathrm{e}^{1} \mathrm{e}^{\mathrm{l}}\right)$

$$
\begin{aligned}
= & \mu_{\mathrm{AxB}}\left(\mathrm{xy}^{-1}, \mathrm{e}^{\prime} \mathrm{e}^{\prime}\right) \\
= & \mu_{\mathrm{AxB}}\left[\left(\mathrm{x}, \mathrm{e}^{\mathrm{l}}\right)\left(\mathrm{y}^{-1}, \mathrm{e}^{\prime}\right)\right] \\
\leq & \mu_{\mathrm{AxB}}\left(\mathrm{x}, \mathrm{e}^{\mathrm{l}}\right) \vee \mu_{\mathrm{AxB}}\left(\mathrm{y}^{-1}, \mathrm{e}^{\prime}\right) \\
= & \left\{\mu_{\mathrm{A}}(\mathrm{x}) \vee \mu_{\mathrm{B}}\left(\mathrm{e}^{\prime}\right)\right\} \\
& \vee\left\{\mu_{\mathrm{A}}\left(\mathrm{y}^{-1}\right) \vee \mu_{\mathrm{B}}\left(\mathrm{e}^{\prime}\right)\right. \\
= & \mu_{\mathrm{A}}(\mathrm{x}) \vee \mu_{\mathrm{A}}\left(\mathrm{y}^{-1}\right) \\
\leq & \mu_{\mathrm{A}}(\mathrm{x}) \vee \mu_{\mathrm{A}}(\mathrm{y}) .
\end{aligned}
$$

Therefore, $\mu_{\mathrm{A}}\left(\mathrm{xy}^{-1}\right) \leq \mu_{\mathrm{A}}(\mathrm{x}) \vee \mu_{\mathrm{A}}(\mathrm{y})$.

We know that $\mu_{\mathrm{A}}(\mathrm{mx}) \leq \mu_{\mathrm{A}}(\mathrm{x})$.

$$
\begin{aligned}
\mu_{\mathrm{A}}(\mathrm{xy})= & \mu_{\mathrm{A}}(\mathrm{xy}) \vee \mu_{\mathrm{B}}\left(\mathrm{e}^{\prime} \mathrm{e}^{\mathrm{l}}\right) \\
= & \mu_{\mathrm{AxB}}\left(\mathrm{xy}, \mathrm{e}^{\prime} \mathrm{e}^{\prime}\right) \\
= & \mu_{\mathrm{AxB}}\left[\left(\mathrm{x}, \mathrm{e}^{\prime}\right)\left(\mathrm{y}, \mathrm{e}^{\prime}\right)\right] \\
= & \mu_{\mathrm{AxB}}\left(\left(\mathrm{y}, \mathrm{e}^{\prime}\right)\left(\mathrm{x}, \mathrm{e}^{\prime}\right)\right) \\
& =\mu_{\mathrm{AxB}}\left(\mathrm{yx}, \mathrm{e}^{\prime} \mathrm{e}^{\prime}\right) \\
= & \mu_{\mathrm{A}}(\mathrm{yx}) \vee \mu_{\mathrm{B}}\left(\mathrm{e}^{\prime} \mathrm{e}^{\prime}\right) \\
= & \mu_{\mathrm{A}}(\mathrm{yx})
\end{aligned}
$$

Hence A is an anti L-fuzzy Normal M-subgroup of G. Thus (i) is proved.

Now, using the property $\mu_{\mathrm{B}}(\mathrm{x}) \geq \mu_{\mathrm{A}}(\mathrm{e})$, for all $\mathrm{x}$ in $\mathrm{G}$, we get, $\mu_{\mathrm{B}}\left(\mathrm{xy}^{-1}\right)=\mu_{\mathrm{B}}\left(\mathrm{xy}^{-1}\right) \vee \mu_{\mathrm{A}}($ ee $)$

$$
\begin{aligned}
& =\mu_{\mathrm{AxB}}\left((\mathrm{ee}),\left(\mathrm{xy}^{-1}\right)\right) \\
& =\mu_{\mathrm{AxB}}\left[(\mathrm{e}, \mathrm{x})\left(\mathrm{e}, \mathrm{y}^{-1}\right)\right] \\
& \leq \mu_{\mathrm{AxB}}(\mathrm{e}, \mathrm{x}) \vee \mu_{\mathrm{AxB}}\left(\mathrm{e}, \mathrm{y}^{-1}\right) \\
& =\left\{\mu_{\mathrm{B}}(\mathrm{x}) \vee \mu_{\mathrm{A}}(\mathrm{e})\right\} \vee\left\{\mu_{\mathrm{B}}\left(\mathrm{y}^{-1}\right) \vee \mu_{\mathrm{A}}(\mathrm{e})\right\}
\end{aligned}
$$

$$
\begin{aligned}
= & \mu_{\mathrm{B}}(\mathrm{x}) \vee \mu_{\mathrm{B}}\left(\mathrm{y}^{-1}\right) \\
& \leq \mu_{\mathrm{B}}(\mathrm{x}) \vee \mu_{\mathrm{B}}(\mathrm{y}) .
\end{aligned}
$$

Therefore, $\mu_{\mathrm{B}}\left(\mathrm{xy}^{-1}\right) \leq \mu_{\mathrm{B}}(\mathrm{x}) \vee \mu_{\mathrm{B}}(\mathrm{y})$, for all $\mathrm{x}$ and $\mathrm{y}$ in $\mathrm{H}$.

We know that $\mu_{\mathrm{B}}(\mathrm{mx}) \leq \mu_{\mathrm{B}}(\mathrm{x})$.

$$
\begin{aligned}
\mu_{\mathrm{B}}(\mathrm{xy}) & =\mu_{\mathrm{A}}(\mathrm{ee}) \vee \mu_{\mathrm{B}}(\mathrm{xy}) \\
& =\mu_{\mathrm{AxB}}(\mathrm{ee}, \mathrm{xy}) \\
& =\mu_{\mathrm{AxB}}[(\mathrm{e}, \mathrm{x})(\mathrm{e}, \mathrm{y})] \\
& =\mu_{\mathrm{AxB}}[(\mathrm{e}, \mathrm{y})(\mathrm{e}, \mathrm{x})] \\
& =\mu_{\mathrm{AxB}}(\mathrm{ee}, \mathrm{yx}) \\
& =\mu_{\mathrm{A}}(\mathrm{ee}) \vee \mu_{\mathrm{B}}(\mathrm{yx}) \\
& =\mu_{\mathrm{B}}(\mathrm{yx})
\end{aligned}
$$

Hence B is an anti L-fuzzy Normal M-subgroup of H. Thus (ii) is proved.

(iii) is clear.

\section{ANTI L-FUZZY NORMAL M- SUBGROUPS OF AN M-GROUP G UNDER HOMOMORPHISM AND ANTI- HOMOMORPHISM}

3.1 Theorem: The homomorphic image of an anti L-fuzzy Msubgroup of $\mathrm{G}$ is an anti L-fuzzy M-subgroup of $\mathrm{G}^{\prime}$

3.2 Theorem: Let $G$ and $G^{\prime}$ be any two M-groups. The homomorphic image of an anti L-fuzzy normal M-subgroup of $\mathrm{G}$ is an anti L-fuzzy normal M-subgroup of $\mathrm{G}^{\prime}$.

Proof: Let $G$ and $G^{\prime}$ be any two M-groups. Let $f: G \rightarrow G^{\prime}$ be a homomorphism.

That is $f(x y)=f(x) f(y), f(m x)=m f(x)$, for all $x$ and $y$ in $G$ and $\mathrm{m}$ in $\mathrm{M}$.

Let $V=f(A)$, where $A$ is an anti L-fuzzy normal M-subgroup of G.

We have to prove that $\mathrm{V}$ is an anti L-fuzzy normal M-subgroup of $\mathrm{G}^{\mathrm{l}}$.

Now, for $f(x)$ and $f(y) \in G^{\prime}$, we have $V$ is an anti L-fuzzy Msubgroup of a M-group $\mathrm{G}^{\mathrm{l}}$,

since $\mathrm{A}$ is an anti L-fuzzy M-subgroup of a M-group G.

Now, $\quad \mu_{\mathrm{V}}(\mathrm{f}(\mathrm{x}) \mathrm{f}(\mathrm{y}))=\mu_{\mathrm{V}}(\mathrm{f}(\mathrm{xy}))$,

as $\mathrm{f}$ is a homomorphism

$\leq \mu_{\mathrm{A}}(\mathrm{xy})=\mu_{\mathrm{A}}(\mathrm{yx})$,

as $A$ is an ALFNMSG of $G$

$\geq \mu_{\mathrm{V}}(\mathrm{f}(\mathrm{yx}))$

$=\mu_{\mathrm{V}}(\mathrm{f}(\mathrm{y}) \mathrm{f}(\mathrm{x}))$,

as $\mathrm{f}$ is a homomorphism,

which implies that $\mu_{\mathrm{V}}(\mathrm{f}(\mathrm{x}) \mathrm{f}(\mathrm{y}))=\mu_{\mathrm{V}}(\mathrm{f}(\mathrm{y}) \mathrm{f}(\mathrm{x}))$.

Hence $\mathrm{V}$ is an anti L-fuzzy normal M-subgroup of a M-group $G^{\prime}$.

3.3 Theorem: The homomorphic pre-image of an anti L-fuzzy M-subgroup of $\mathrm{G}^{\prime}$ is an anti L-fuzzy M-subgroup of $\mathrm{G}$. 
3.4 Theorem: Let $G$ and $G^{\prime}$ be any two M-groups. The homomorphic pre-image of an anti L-fuzzy normal M-subgroup of $\mathrm{G}^{\prime}$ is an anti L-fuzzy normal M-subgroup of $\mathrm{G}$.

Proof: Let $G$ and $G^{\prime}$ be any two M-groups. Let $f: G \rightarrow G^{\prime}$ be a homomorphism.

That is $f(x y)=f(x) f(y), f(m x)=m f(x)$, for all $x$ and $y$ in $G$ and $\mathrm{m}$ in $\mathrm{M}$.

Let $\mathrm{V}=\mathrm{f}(\mathrm{A})$, where $\mathrm{V}$ is an anti L-fuzzy normal M-subgroup of $\mathrm{G}^{\mathrm{l}}$.

We have to prove that $\mathrm{A}$ is an anti L-fuzzy normal M-subgroup of $\mathrm{G}$.

Let $\mathrm{x}$ and $\mathrm{y}$ in $\mathrm{G}$. Then, we know that, $\mathrm{A}$ is an anti L-fuzzy Msubgroup of a M-group G,

since $\mathrm{V}$ is an anti L-fuzzy M-subgroup of a M-group $\mathrm{G}^{\prime}$.

Now, $\mu_{\mathrm{A}}(\mathrm{xy})=\mu_{\mathrm{V}}(\mathrm{f}(\mathrm{xy}))$,

$$
\begin{aligned}
& \text { since } \mu_{A}(x)=\mu_{V}(f(x)) \\
= & \mu_{V}(f(x) f(y)), \\
& \quad \mu_{V}(f(y) f(x)), \\
& \text { as } \mathrm{V} \text { is a hom an ALFNMSG of } G^{\prime} \\
= & \mu_{V}(f(y x)), \\
= & \mu_{A}(y x), \\
\text { as } f \text { in a homomorphism } & \mu_{A}(x)=\mu_{V}(f(x)),
\end{aligned}
$$

which implies that $\mu_{\mathrm{A}}(\mathrm{xy})=\mu_{\mathrm{A}}(\mathrm{yx})$.

Hence A is an anti L-fuzzy normal M-subgroup of a M-group G.

3.5 Theorem: The anti-homomorphic image of an anti L-fuzzy normal M-subgroup of $\mathrm{G}$ is an anti L-fuzzy M-subgroup of $\mathrm{G}^{\prime}$.

3.6 Theorem: Let $G$ and $G^{\prime}$ be any two M-groups. The antihomomorphic image of an anti L-fuzzy normal M-subgroup of $\mathrm{G}$ is an anti L-fuzzy normal M-subgroup of $\mathrm{G}^{\prime}$.

Proof: Let $G$ and $G^{\prime}$ be any two M-groups. Let $f: G \rightarrow G^{\prime}$ be an anti-homomorphism.

That is $f(x y)=f(y) f(x), f(m x)=f(x) m$, for all $x$ and $y$ in $G$ and $\mathrm{m}$ in $\mathrm{M}$.

Let $V=f(A)$, where $A$ is an anti L-fuzzy normal M-subgroup of G.

We have to prove that $\mathrm{V}$ is an anti L-fuzzy normal M-subgroup of $\mathrm{G}^{\prime}$.

For $f(x)$ and $f(y) \in G^{\prime}$, we know that, $V$ is an anti L-fuzzy Msubgroup of a M-group $\mathrm{G}^{\prime}$,

since A is an anti L-fuzzy M-subgroup of a M-group G.

Now,

$$
\begin{gathered}
\mu_{\mathrm{V}}(\mathrm{f}(\mathrm{x}) \mathrm{f}(\mathrm{y}))=\mu_{\mathrm{V}}(\mathrm{f}(\mathrm{yx})), \\
\text { as } \mathrm{f} \text { is an anti-homomorphism } \\
\leq \mu_{\mathrm{A}}(\mathrm{yx})=\mu_{\mathrm{A}}(\mathrm{xy}), \\
\text { as } \mathrm{A} \text { is an ALFNMSG of } \mathrm{G} \\
\geq \mu_{\mathrm{V}}(\mathrm{f}(\mathrm{xy}))=\mu_{\mathrm{V}}(\mathrm{f}(\mathrm{y}) \mathrm{f}(\mathrm{x})), \\
\text { as } \mathrm{f} \text { is an anti-homomorphism, }
\end{gathered}
$$

which implies that $\mu_{\mathrm{V}}(\mathrm{f}(\mathrm{x}) \mathrm{f}(\mathrm{y}))=\mu_{\mathrm{V}}(\mathrm{f}(\mathrm{y}) \mathrm{f}(\mathrm{x}))$.
Hence $\mathrm{V}$ is an anti L-fuzzy normal M-subgroup of a M-group $\mathrm{G}^{\prime}$.

3.7 Theorem: Let $G$ and $G^{\prime}$ be any two M-groups. The antihomomorphic pre-image of an anti L-fuzzy M-subgroup of $\mathrm{G}^{\prime}$ is an anti L-fuzzy M-subgroup of G.

3.8 Theorem: Let $G$ and $G^{\prime}$ be any two M-groups. The antihomomorphic pre-image of an anti L-fuzzy normal M-subgroup of $\mathrm{G}^{\prime}$ is an anti L-fuzzy normal M-subgroup of $\mathrm{G}$.

Proof: Let $G$ and $G^{\prime}$ be any two M-groups. Let $f: G \rightarrow G^{\prime}$ be anti-homomorphism.

That is $f(x y)=f(y) f(x), f(m x)=f(x) m$, for all $x$ and $y$ in $G$ and $\mathrm{m}$ in $\mathrm{M}$.

Let $\mathrm{V}=\mathrm{f}(\mathrm{A})$, where $\mathrm{V}$ is an anti L-fuzzy normal M-subgroup of $\mathrm{G}^{\prime}$.

We have to prove that A is an anti L-fuzzy normal M-subgroup of $\mathrm{G}$.

Let $\mathrm{x}$ and $\mathrm{y}$ in $\mathrm{G}$, we have, $\mathrm{A}$ is an anti L-fuzzy M-subgroup of a M-group G,

since $\mathrm{V}$ is an anti L-fuzzy M-subgroup of a M-group $\mathrm{G}^{\prime}$.

Now, $\mu_{\mathrm{A}}(\mathrm{xy})=\mu_{\mathrm{V}}(\mathrm{f}(\mathrm{xy}))$,

$$
\begin{aligned}
\text { since } \mu_{\mathrm{A}}(\mathrm{x})=\mu_{\mathrm{V}}(\mathrm{f}(\mathrm{x})) \\
=\mu_{\mathrm{V}}(\mathrm{f}(\mathrm{y}) \mathrm{f}(\mathrm{x})), \\
\quad \text { as } \mathrm{f} \text { is an anti homomorphism } \\
=\mu_{\mathrm{V}}(\mathrm{f}(\mathrm{x}) \mathrm{f}(\mathrm{y})), \\
\quad \text { as } \mathrm{V} \text { is an ALFNMSG of } \mathrm{G}^{\prime} \\
=\mu_{\mathrm{V}}(\mathrm{f}(\mathrm{yx})), \\
\quad \text { as } \mathrm{f} \text { is an anti homomorphism } \\
=\mu_{\mathrm{A}}(\mathrm{yx}) \text {, since } \mu_{\mathrm{A}}(\mathrm{x})=\mu_{\mathrm{V}}(\mathrm{f}(\mathrm{x})),
\end{aligned}
$$

which implies that $\mu_{\mathrm{A}}(\mathrm{xy})=\mu_{\mathrm{A}}(\mathrm{yx})$.

Hence A is an anti L-fuzzy normal M-subgroup of a M-group G.

\section{In the following Theorem $\circ$ is the composition operation of functions:}

3.9 Theorem: Let A be an anti L-fuzzy M-subgroup of a Mgroup $\mathrm{H}$ and $\mathrm{f}$ is an isomorphism from a $\mathrm{M}$-group $\mathrm{G}$ onto $\mathrm{H}$. If $\mathrm{A}$ is an anti L-fuzzy normal $\mathrm{M}$-subgroup of a $\mathrm{M}$-group $\mathrm{H}$, then $\mathrm{A} \circ \mathrm{f}$ is an anti L-fuzzy normal M-subgroup of a M-group $\mathrm{G}$.

Proof: Let $\mathrm{x}$ and $\mathrm{y}$ in $\mathrm{G}$ and $\mathrm{A}$ be an anti L-fuzzy normal Msubgroup of a M-group $\mathrm{H}$.

We know that, $\mathrm{A} \circ \mathrm{f}$ is an anti L-fuzzy M-subgroup of a M-group G.

Then we have,

$$
\begin{aligned}
\left(\mu_{\mathrm{A}} \circ \mathrm{f}\right)(\mathrm{xy}) & =\mu_{\mathrm{A}}(\mathrm{f}(\mathrm{xy})) \\
& =\mu_{\mathrm{A}}(\mathrm{f}(\mathrm{x}) \mathrm{f}(\mathrm{y})), \\
& =\mu_{\mathrm{A}}(\mathrm{f}(\mathrm{y}) \mathrm{f}(\mathrm{x})), \\
& \text { as } \mathrm{A} \text { is an AL an isomorphism } \\
& =\mu_{\mathrm{A}}(\mathrm{f}(\mathrm{yx})), \text { as } \mathrm{f} \text { is an isomorphism } \\
& =\left(\mu_{\mathrm{A}} \circ \mathrm{f}\right)(\mathrm{yx}),
\end{aligned}
$$

which implies that $\left(\mu_{\mathrm{A}} \circ \mathrm{f}\right)(\mathrm{xy})=\left(\mu_{\mathrm{A}} \circ \mathrm{f}\right)(\mathrm{yx})$. 
Hence $A \circ f$ is an anti L-fuzzy normal M-subgroup of a M-group G.

3.10 Theorem: Let A be an anti L-fuzzy M-subgroup of a Mgroup $\mathrm{H}$ and $\mathrm{f}$ is an anti-isomorphism from a $\mathrm{M}$-group $\mathrm{G}$ onto $\mathrm{H}$. If $\mathrm{A}$ is an anti L-fuzzy normal $\mathrm{M}$-subgroup of a $\mathrm{M}$-group $\mathrm{H}$, then $\mathrm{A} \circ \mathrm{f}$ is an anti L-fuzzy normal M-subgroup of a M-group $\mathrm{G}$.

Proof: Let $\mathrm{x}$ and $\mathrm{y}$ in $\mathrm{G}$ and $\mathrm{A}$ be an anti L-fuzzy normal $\mathrm{M}$ subgroup of a M-group $\mathrm{H}$.

We know that, A॰f is an anti L-fuzzy M-subgroup of a M-group G.

Then we have,

$$
\begin{aligned}
\left(\mu_{\mathrm{A}} \circ \mathrm{f}\right)(\mathrm{xy}) & =\mu_{\mathrm{A}}(\mathrm{f}(\mathrm{xy})) \\
& =\mu_{\mathrm{A}}(\mathrm{f}(\mathrm{y}) \mathrm{f}(\mathrm{x})), \\
& \text { as } \mathrm{f} \text { is an anti-isomorphism } \\
& =\mu_{\mathrm{A}}(\mathrm{f}(\mathrm{x}) \mathrm{f}(\mathrm{y})), \\
& \text { as A is an ALFNMSG of a group } \mathrm{H} \\
= & \mu_{\mathrm{A}}(\mathrm{f}(\mathrm{yx})), \\
& \text { as } \mathrm{f} \text { is an anti-isomorphism } \\
= & \left(\mu_{\mathrm{A}} \circ \mathrm{f}\right)(\mathrm{yx}),
\end{aligned}
$$

which implies that $\left(\mu_{\mathrm{A}} \circ \mathrm{f}\right)(\mathrm{xy})=\left(\mu_{\mathrm{A}} \circ \mathrm{f}\right)(\mathrm{yx})$.

Hence $(\mathrm{A} \circ \mathrm{f})$ is an anti L-fuzzy normal M-subgroup of a $\mathrm{M}$ group $\mathrm{G}$.

\section{CONCLUSIONS}

Further work is in progress in order to develop the Intuitionistic Fuzzy normal M-subgroup and Intuitionistic Anti L-Fuzzy normal M-subgroup.

\section{REFERENCES}

[1] Azriel Rosenfeld, Fuzzy Groups, Journal of mathematical analysis and applications 35, (1971) 512-51.

[2] R. Biswas, Fuzzy subgroups and anti-fuzzy subgroups, Fuzzy Sets and Systems 35 (1990), 121-124.

[3] J.A. Goguen, L-fuzzy sets, J. Math. Anal. Appl.18 (1967), $145-179$

[4] Mohamed Asaad, Groups and Fuzzy Subgroups, Fuzzy Sets and Systems 39 (1991) 323-328.

[5] Prabir Bhattacharya, Fuzzy subgroups: Some characterizations, J. Math. Anal. Appl. 128 (1981) 241-252.

[6] N.Palaniappan, R.Muthuraj, The homomorphism, Antihomomorphism of a fuzzy and an anti-fuzzy group, Varahmihir Journal of mathematical Sciences, 4 (2)(2004) 387-399.

[7] N.Palaniappan , S. Naganathan, \& K. Arjunan, A Study on Intuitionistic L-Fuzzy Subgroups, Applied mathematical Sciences, 3 (53) (2009) 2619-2624.

[8] P.Pandiammal, R.Natarajan, N.Palaniappan, Anti L-fuzzy M-subgroups, Antartica Journal of Mathematics, Accepted for publications.

[9] P.Pandiammal, R.Natarajan, N.Palaniappan, A Study on Lower Level subsets of Anti L-fuzzy M-subgroups, Antartica Journal of Mathematics, Accepted for publications.

[10] L.A. Zadeh, Fuzzy sets, Information and control, 8, (1965) 338-353. 